\title{
2020 Syndemic: Convergence of COVID-19, Gender-Based Violence, and Racism Pandemics
}

\author{
Nazilla Khanlou ${ }^{1}$ (1) $\cdot$ Luz Maria Vazquez $^{1}$ - Soheila Pashang ${ }^{2}$. Jennifer A. Connolly ${ }^{1}$. Farah Ahmad ${ }^{1}$. Andrew Ssawe ${ }^{3}$
}

Received: 4 January 2021 / Revised: 27 March 2021 / Accepted: 3 September 2021 / Published online: 14 October 2021

(c) The Author(s) 2021

\begin{abstract}
Objective To conduct a rapid knowledge synthesis of literature on the social determinants of mental health of racialized women exposed to gender-based violence (GBV) during the COVID-19 pandemic.

Methods We adapted the Cochrane Rapid Reviews method and were guided by an equity lens in conducting rapid reviews on public health issues. Four electronic databases (Cochrane CENTRAL, Medline, ProQuest, and EBSCO), electronic news media, Google Scholar, and policy documents were searched for literature between January 2019 and October 2020 with no limitations for location. Fifty-five articles qualified for the review.

Results Health emergencies heighten gender inequalities in relation to income, employment, job security, and working conditions. Household stress and pandemic-related restrictions (social distancing, closure of services) increase women's vulnerability to violence. Systemic racism and discrimination intensify health disparities.

Conclusion Racialized women are experiencing a 2020 Syndemic: a convergence of COVID-19, GBV, and racism pandemics, placing their wellbeing at a disproportionate risk. GBV is a public health issue and gender-responsive COVID-19 programming is essential. Anti-racist and equity-promoting policies to GBV service provision and disaggregated data collection are required.
\end{abstract}

Keywords COVID-19 $\cdot$ Racism $\cdot$ Gender-based violence $\cdot$ Mental health $\cdot$ Pandemics

\section{Introduction}

The COVID-19 pandemic has led to differential health, social, and economic impacts on populations, illuminating the prevailing inequalities that reinforce disadvantage for marginalized segments of the public [1,2]. Among the disturbing outcomes of the pandemic is the global rise in gender-based violence (GBV) [3], including sexual assault and rape, experienced by women [4]. The United Nations has referred to this alarming societal problem as the "shadow

Nazilla Khanlou

nkhanlou@yorku.ca

1 Faculty of Health, York University, 4700 Keele Street, ON M3J 1P3 Toronto, Canada

2 Faculty of Social and Community Services, Humber Institute of Technology and Advanced Learning, ON, Toronto, Canada

3 Newcomers, Families and Clinical Programs and Services, South Riverdale Community Health Centre, ON, Toronto, Canada pandemic" [3]. Fear, uncertainties, and stressors among the population during the pandemic can increase anger and aggression and further lead to victimization of women [5]. This is of concern given that in the 12 months previous to the COVID-19 pandemic, 243 million women and girls (aged 15-49) around the world were subjected to sexual and/ or physical violence [5].

Gender-based violence is perpetrated against individuals based on their perceived gender, gender identity, or gender expression and may include a range of human rights violations, such as rape, domestic violence, sexual assault and harassment, trafficking of women and girls, and sexual abuse of children. Estimates show GBV impacts the mental, physical, and sexual health of an alarming 30-60\% of women globally [6]. Violence against women contributes to high levels of morbidity and mortality [7]. The life-long impacts of GBV include psychological distress, anxiety disorders (post-traumatic stress disorder), depression, and substance use disorders [8]. Higher rates of past suicide attempts [7, 9] social exclusion, and isolation among women have also been reported [8]. Violence against women is rooted in 
discrimination and inequality that are sustained and reproduced by systems and structures as well as social norms.

Life free of violence is a fundamental human right and to achieve equality and nondiscrimination a lot more needs to be done to address GBV. This has become crucial under the pandemic with escalating GBV incidents [4]. Addressing this urgent public health and policy and practice need, our team conducted a rapid knowledge synthesis of the literature with a focus on racialized women. We looked at the racialized and gendered social determinants of mental health among women exposed to genderbased violence during the COVID-19 pandemic. We report on the literature review methods and synthesis findings in this paper. Overall, we found that racialized women are experiencing what we name as a 2020 Syndemic: a convergence of COVID-19, gender-based violence, and racism pandemics, placing their wellbeing at a disproportionate risk. The term syndemic refers to two or more epidemics [10]. A syndemic lens illuminates how diseases are aggravated by socioeconomic, political, or environmental contexts, and how they interact, leading to synergistic vulnerability to diseases and social inequities [11].

\section{An Intersectional Approach to COVID-19 as a Syndemic}

A syndemic framework integrates two processes: (i) disease concentration (clustering of multiple epidemics, which results from political economic contexts); and (ii) disease interaction (to explain how multiple epidemics exacerbate health effect in contexts of "adverse social conditions") [12]. The concept emerged in the 1990s, coined by medical anthropologist Merrill Singer [13]. Singer et al. explain [14] that syndemics are most likely to emerge in the context of health and socioeconomic inequalities including poverty, stigmatization, stress, or structural violence, because these factors account for disease clustering and exposure, and also promote increased physical and behavioral vulnerability.

Horton [15] states that the COVID-19 is not a pandemic, but a syndemic, and that we need to look at the contexts of socioeconomic inequalities that are disproportionally impacting particular marginalized groups in our society. Horton emphasizes that viewing COVID-19 as a syndemic points out its underlining social origins [15]. A focus on the social dimensions allows us to better understand the factors which contribute to the formation of disease, its clustering, and its spread [16]. It also allows an understanding of conditions which further contribute to disease progression such as reducing an individual's immune function and increasing susceptibility to disease [16]. A syndemic perspective then is a lens to explain why certain individuals, families, or communities are more vulnerable than others [10]. Violence is considered a dimension of syndemics and was first integrated into this approach in the analysis of substance abuse and HIV [17]. Researchers apply, for example, the concept of social comorbidities to refer to family and community violence, sexual assault, childhood sexual abuse, depression, and substance abuse, as behavioral and social phenomena aspects of violence against women [17].

While a good start to addressing compounding health risks, the epidemiologic lens needs to be coupled with critical perspectives to address complex social inequities and marginalization $[15,18]$. In our studies on mental health support for racialized women at risk of gender-based violence, we apply an intersectionality-informed approach to analyzing the combined impacts of racism, sexism, and social inequities. An intersectionality lens, we believe, enables us to examine how gender intersects with the social determinants of health, leading to gendered health disparities pathways, and resulting in synergistic health disadvantage for certain segments of the population, including racialized women at risk of genderbased violence during COVID-19 pandemic's response and recovery phases.

Intersectionality is an analytical approach for understanding and responding to the ways in which gender intersects with identity markers-including race, socioeconomic status, dis(ability), sexual orientation, migration status, ethnicity - and how these intersections contribute to unique experiences of privilege and oppression $[19,20]$ People live multiple, layered identities, derived from social relations, history, and the operation of structures of power [20]. Women's experiences are influenced by social identities that are impacted by power/lessness, marginalization, and structural inequities. Therefore, how women address violence, the resources they have, the barriers they face to access the services they need, the resiliency they have to cope with adversity, is informed and influenced by the contextual intersections [20]. We can think of intersectionality as an approach for development and human rights work, and to promoting a social justice action agenda. It has been argued that the frameworks of intersectionality and syndemics "are rarely brought together" [18]. Through sharing findings of our rapid synthesis review, we hope to inform public health interventions addressing GBV, and to efforts mitigating the negative social determinants of mental health impacts of the COVID-19 syndemic on racialized women.

\section{Methods}

We adapted the Cochrane COVID Rapid Reviews Method [21] in conducting rapid reviews on public health issues. Our methods were guided by the Centers for Disease Control and Prevention (CDCP) [22] Equity Lens, which considers the many health inequities (such as health care access and utilization, discrimination, education, income, wealth gaps, occupation, and housing) that put racial and ethnic minority groups at increased risk during the COVID-19 pandemic. 
The review included the following six steps. In Step one, we identified two research questions: (i) "What are the racialized and gendered social determinants of mental health among racialized women and girls with experiences of GBV?"; and (ii) "What are the emerging best practices/evidence of effectiveness of services or implementation for equity-informed mental health promotion and health care provision for this population during the current COVID-19 pandemic?". In Step two, we set the study selection criteria (study inclusion criteria): PICO was applied: Population: women and/or girls 15 years and older at risk of GBV and experiencing GBV. Intervention: published studies assessing/addressing GBV and mental health outcomes (including interventions/initiatives) during the COVID-19 pandemic. There were no Comparators. Outcomes: identified emerging guidelines. Step three involved a search strategy to identify relevant studies. Searches were conducted across four electronic databases (Cochrane CENTRAL, Medline, ProQuest, and EBSCO). We examined ongoing/unpublished studies through grey literature searching of websites, including electronic news media, Google Scholar, and policy documents, between the years 2019 and October 2020. The search strategy and keywords were developed by the research team members and approved by the principal investigator (first author) and a health sciences librarian (Table 1).

Data collection was completed in Step four. Key characteristics of selected studies/articles were recorded after reviewing 286 items including journal articles, book chapters, and grey literature. For the final review, 55 articles met the eligibility criteria ( 15 peer-reviewed and 40 grey literature). Excluded sources included duplicates and material that did not focus on violence against women and girls, social determinants of health, best practices, or recommendations. Analysis and synthesis were completed in steps 5 and 6. In Step five, emerging review findings were organized along following the overall themes: (1) COVID-19 social determinants of health and impacts on women; (2) Genderbased violence risk factors during a pandemic; and (3) Racism, discrimination, and health outcomes. We interpreted the public health implications of the findings through an

Table 1 Search terms

\begin{tabular}{ll}
\hline Key & Search Terms \\
\hline 1 & women, woman, gender \\
2 & $\begin{array}{c}\text { violence, abuse, stress, domestic violence, intimate partner } \\
\text { violence }\end{array}$ \\
3 & health, mental health, wellbeing, well being \\
4 & pandemic, COVID, coronavirus \\
5 & migrant*, immigrant*, precarious status, racial*, race, Asia*, \\
& $\begin{array}{l}\text { Latin*, Hispanic, Black, African American, Indigenous, abo- } \\
\text { riginal, native, ethnic minority, minority, ethnocultural }\end{array}$ \\
\hline
\end{tabular}

intersectionality-informed lens. In Step six, we considered applicability and transferability of the findings through application of a syndemic understanding of the themes and identification of multilevel interventions (Fig. 1).

\section{Results}

The findings of our rapid synthesis address three significant and overlapping areas, as outlined in further detail in the following sections.

\section{COVID-19 Social Determinants of Health and Impacts on Women}

Experiences from previous epidemics indicate that women's burdens (physical, psychological, and time) increase during health emergencies [5]. In the context of the current COVID19 pandemic, this is not the exception. Health emergencies heighten pervasive existing gender inequalities. Crises increase women's vulnerabilities given they are more likely than men to work in informal and precarious minimum wage jobs [23], and as frontline providers [9], representing 70\% of the health and social care workforce around the world [24]. Women engage in frontline health, social services, and cleaning professions, which place them at higher risk in the current pandemic. Depending on location, it is important to note the racialized and gendered nature of the workforce for essential frontline workers. Disproportionate impacts of precarious work on women are recognized by the United Nations which states that:

"not enough attention is given to how their [women] work environment may be discriminatory, as well as what their sexual and reproductive health and psychosocial needs are as frontline health workers" [25]. page 1

During the pandemic, women's domestic burden has also increased. In general, most of the caregiving at home is provided by women. With the pandemic, unpaid caregiving work by women and girls has increased [26]. For example, taking care of children who are at home due to school closures disproportionally impacts women [24]. Women are also the main caregivers of those infected by the virus within the household, increasing their unpaid housework and also putting them at higher risk [25]. Outside the home, workplace violence has increased against female health care workers in China, Italy, and Singapore [27]; and in the USA, there have been reports of increased violence directed at street-based sex workers [27]. Victims of sex trafficking are among the most vulnerable and marginalized groups at risk and this can affect underage girls as well as women [28, 29]. 


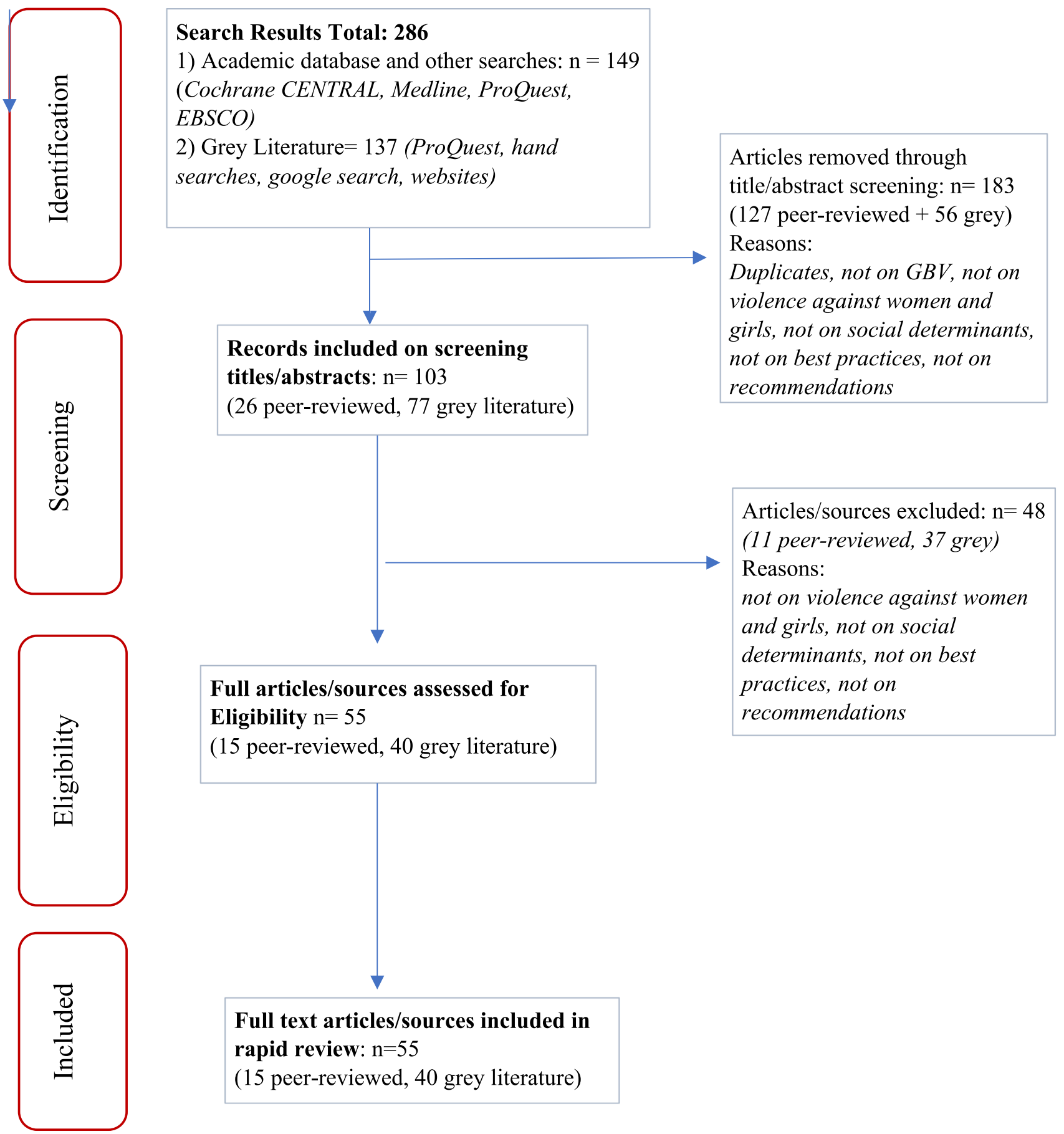

Fig. 1 PRISMA diagram—rapid review search results

\section{Gender-Based Violence Risk Factors During a Pandemic}

Structural and systemic factors in the context of the COVID19 pandemic impact violence against women and girls [30]. Poverty, under/unemployment, informal precarious work, and overall financial challenges result in increased household stress, and higher rates of exploitative, transactional sex among girls. Women with precarious immigration status or non-status are at increased risk. Factors that contribute to increased risks for immigrants include stress associated with migration, change in social networks and supports, change in gender roles and responsibilities, and economic insecurity [31]. Women with precarious status are excluded from government relief programs because access to such programs is dependent on legal residency status [9]. Immigrant and 
refugee women and girls may face specific barriers to reporting GBV and seeking help including, for example, fear of loss of children due to deportation, limited knowledge about their rights, and services available, and discrimination and racism.

Social distancing, reduced community interactions, restriction of movement, and closure of services limit women's ability to distance from their abusers and to access the supports they need [5]. This is of particular concern for marginalized groups like Indigenous Peoples who worldwide face increased risks of family violence (for example, Native American women face victimization at rates that are two and a half higher than Caucasians; and in Canada Indigenous women experience it two and a half times than non-Indigenous women) [32]. Previous emergencies have shown that women and other marginalized groups face reduced access to services, for example, in relation to abortion, HIV, and mental health services. Reduction and diversion of resources for essential services impact women's sexual and reproductive health. In past crises, this resulted in "increased rates and sequelae from unintended pregnancies, unsafe abortions, sexually transmitted infections... posttraumatic stress disorder, depression, suicide, intimate partner violence, and maternal and infant mortality" [33]. page1176 During the Ebola outbreak in Sierra Leone, more women died of obstetric complications than of the virus itself [33]. The UNICEF [24] reported that life-saving care and support services for gender-based violence survivors, including clinical management of rape, mental health services, and psycho-social support, are disrupted in tertiary level hospitals given that health service providers are overburdened and preoccupied with handling COVID-19 cases. Hall et al. [33] note that international responses to COVID-19 perpetuate a disregard for sexual and reproductive health and further contribute to justice inequities that impact negatively on the wellbeing, health, and economic stability of women and vulnerable populations in general.

The closure of schools as part of COVID-19-related measures has further disrupted girls' education. A study on the gendered effects of school closures during the COVID19 pandemic reports teenage girls in developing countries may disproportionately drop out of school due to increased risk of pregnancy, forced marriage, and sexual exploitation [34]. The burden of unpaid household work has also disproportionately affected girls. Girls between 5 and 14 years are spending $40 \%$ more time than boys doing unpaid work at home; as a result, girls may spend less time studying or may drop out of school [34].

Pandemics like COVID-19 exacerbate not only violence within the home, but other forms of violence against women occurring outside of the home. Scholars refer to the concept of structural violence to encompass the "often-hidden ways" that poverty, racism, discrimination, and other systems of inequality (such as health) impact the lives of marginalized populations [14]. For example, racism and xenophobia in the workplace have also been reported in the context of the current COVID-19 pandemic. In a recent survey conducted with health care workers in Manitoba, Canada, it was found that 1 in 5 workers who identified as Asian experienced racism in the workplace $[1,35]$. Increase in workplace violence towards female health care workers during the pandemic has been reported in China, Italy, and Singapore [27]. Sinlcair and colleagues [36] recommend deploying mental health support to racial minority workers, in particular Asian workers, because of the micro- and macro-aggressions they likely experience during the pandemic.

\section{Racism, Discrimination, and Health Outcomes}

Racialized communities bear a disproportionate burden of stress, illness, and health inequities, and racism is a systemic risk factor. In the USA, alarming rates of COVID19 infections and deaths among Black Americans, and overall disproportionate impacts on racialized people from ethnic minority backgrounds, illustrate health inequalities [22]. Racialized populations, including Indigenous peoples across the world, are the hardest hit in this pandemic; where their social determinants of health are jeopardized by poverty, inequitable access to medical care or health advice, inadequate housing, precarious employment, and immigration status [32, 37, 38]. Reports show the death rate from COVID-19 among African Americans is 2.4 times the death rate of White Americans in the USA [39]. Similar findings have been reported in Toronto, Canada; the pandemic has had a greater impact on Black and other racialized populations. Black and other racialized groups constitute nearly half of Toronto's population but represented $83 \%$ of reported COVID-19 cases [40]. Furthermore, Black individuals make up $9 \%$ of the city's population, yet they represented $21 \%$ of the reported cases [40].

Overcrowded and low-income households are disproportionately impacted by the pandemic [40]. Experiencing health disparities, as a result of the socioeconomic circumstances, stress related to racism and discrimination, and work requiring close contact with others, prevents following public health responses to COVID-19 [40]. It is in this context that researchers and advocates have highlighted the need to address the lack [41] or inconsistency [42] of data collection in relation to key indicators, such as race, ethnic, gender, age, ability, sexual identity, to fully understand the impacts of the pandemic on marginalized groups.

The concomitant effects of the COVID-19 pandemic and violence against women amplify health inequities. Furthermore, systemic racism with its accompanying discrimination and prejudice contributes to barriers in accessing sexual 
and reproductive health care for racialized women. In North America, historic institutional mistreatment, racism and discrimination against Indigenous communities, and lack of services run by Indigenous people are among the barriers to women and girls seeking survivors' services [35]. Disparities in access and availability to health and mental health care services increase the vulnerabilities of women and girls [9]. In the Canadian context, there have been high rates of reported homicide and suicide among Indigenous communities, which also put women and girls and people from other sexual orientation at higher risk [9]. For example, between 2011 and 2016, statistics show that suicide rates were 3 times higher among First Nations people than among non-Indigenous people; disparities between the two groups were wider among age groups under 15 years, and especially among females between 15 and 24 years of age [43]. Housing shortage, substandard housing, and lack of safe houses and shelters on reserves increase the risk to violence faced by First Nations women, girls, and children [38]. Longstanding inequities in the funding of child welfare services, along with COVID-19 social isolation measures, increase the risk faced by First Nations women, girls, and children, who are disproportionately affected by physical, domestic, and sexual violence [38]. Issues of trust in public institutions and agencies providing services also create barriers to accessing services for survivors, impacting them negatively [35].

Xenophobia and racism during the pandemic have increased. In Canada, racialized individuals were three times more likely than the rest of the population to perceive increases in the frequency of harassment, attacks based on race, ethnicity, or skin color. In particular, 1 in 3 racialized women felt unsafe compared with racialized men ( 1 in 5) [44]. Racist stereotypes against individuals from Asian background have also resurfaced during the current COVID-19 pandemic; in less than a month, a total of more than 1700 anti-Asian hate incidents were documented in the USA [45].

In light of this setting, it is not surprising that the mental health impacts of COVID-19, the "fourth pandemic," will be the biggest aftermath of the pandemic and the greatest impact of the health footprint will be borne by marginalized and racialized populations [46]. Mental health experts predict acute rise in psychiatric disorders and a "tsunami" of mental health issues, and higher risks of poor psychological wellbeing among marginalized populations [47]. Among them are women, low-income families, individuals with limited social support network, and those experiencing social isolation, economic stress, stigma, racism, and social exclusion. For example, a survey in Canada illustrates that during the pandemic Indigenous women are experiencing higher rates of violence and are, therefore, more concerned about intimate violence than COVID-19-related issues (such as financial) [48]. Indigenous Peoples were also more likely to have suicidal thoughts (16\% vs $6 \%$ for others), and feel depressed (31\% vs $23 \%$ for others) [49]; and fear of domestic violence was reported twice as likely among racialized people and high among Indigenous Peoples [46] (Table 2).

\section{Discussion: Public Health Implications}

We applied an intersectionality perspective to understand how gender intersects with the social determinants of health, leading to gendered and racialized pathways in health disparities, and resulting in synergistic health disadvantage. This disparity is higher among certain segments of the population, including Indigenous, Black, and other racialized women at risk of gender-based violence during COVID-19 pandemic's response and recovery phases (Fig. 2). The pandemic's disproportionate risks and impacts bring into light historic, systemic, and structural inequalities at the intersection of racial and ethnic minority status, occupation, and class. As Horton notes, a purely biomedical solution to tackling COVID-19 will likely fail, no matter how effective COVID-19 vaccines and treatments may be because the truth that lies behind these vulnerabilities is barely admitted (2020, p. 874).

Informed by our synthesis review, in Table 3 we highlight public health and mental health implications. International organizations and advocates have recommended that to promote gender equality, and address violence and discrimination, it is imperative to integrate gender-responsive programming into countries' strategic plans for COVID-19 preparedness and response $[26,50]$. Scholars applying a syndemic approach have pointed out the political, economic, and social intersecting factors that, in the context of power inequalities, increased the vulnerabilities and susceptibilities of women to health risks like HIV/AIDS [51]. Our review underscores that COVID-19 response strategies should take into account gendered roles and dynamics, power relations, and responsibilities [24]. By integrating a gender-specific lens, we may be able to consider invisible factors, such as the burden of paid and unpaid care work for women during the health emergency and GBV risks, in planning and response programming [24]. Applying a gender-specific lens we may be able to oversee governments' responses to the health emergency by asking: whether these interventions ensure that women and girls have access to protection, resources, and shelters as essential services; what is being done to curb the impact of the outbreak on support services for survivors, particularly health care, police, and justice services; how specific actions to protect women survivors of violence have been adapted and included in the emergency measures; about the codes of conduct in place to address the endemic violence against female health workers and sexual harassment in the health and social sectors; and about measures 


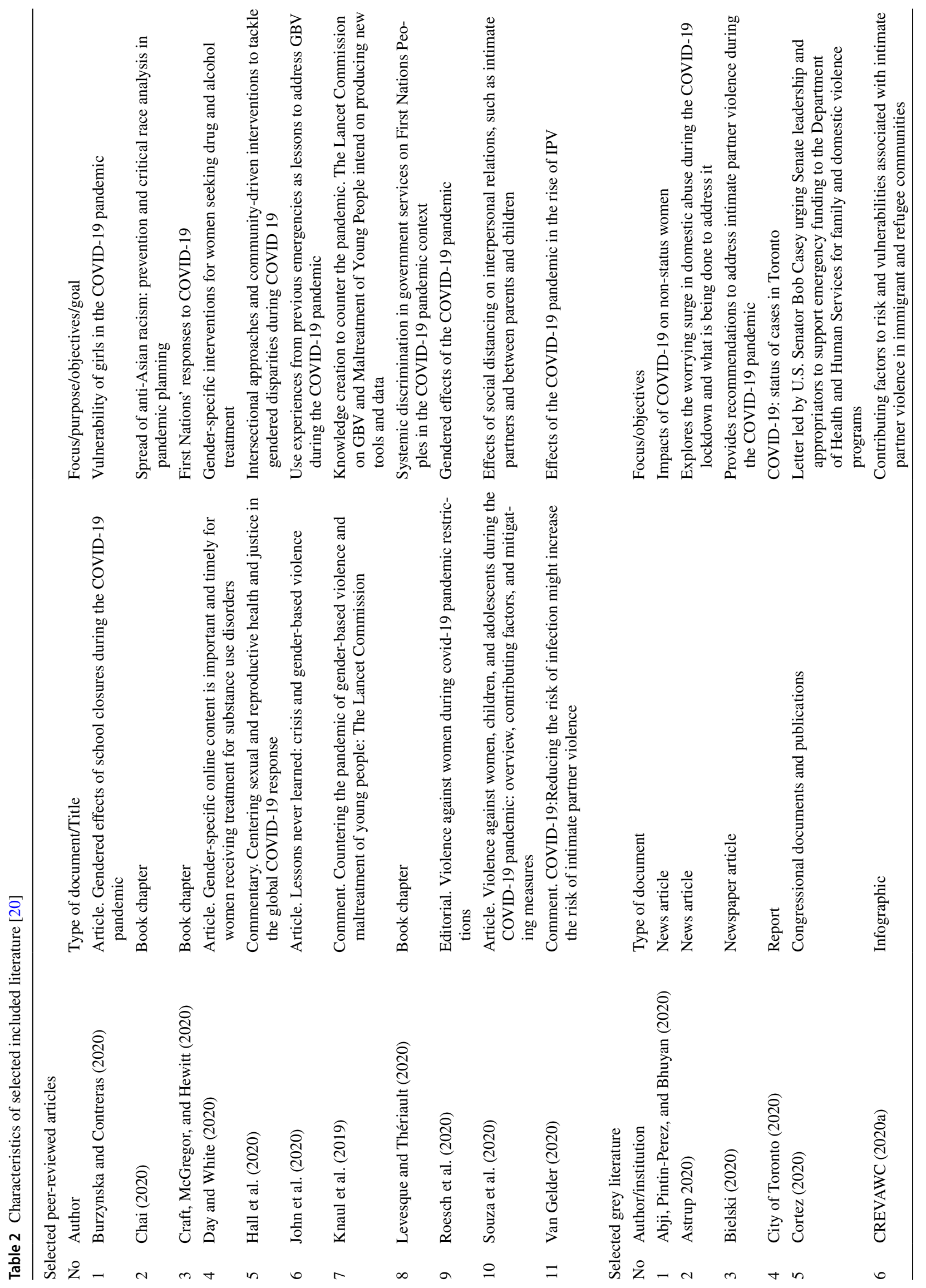




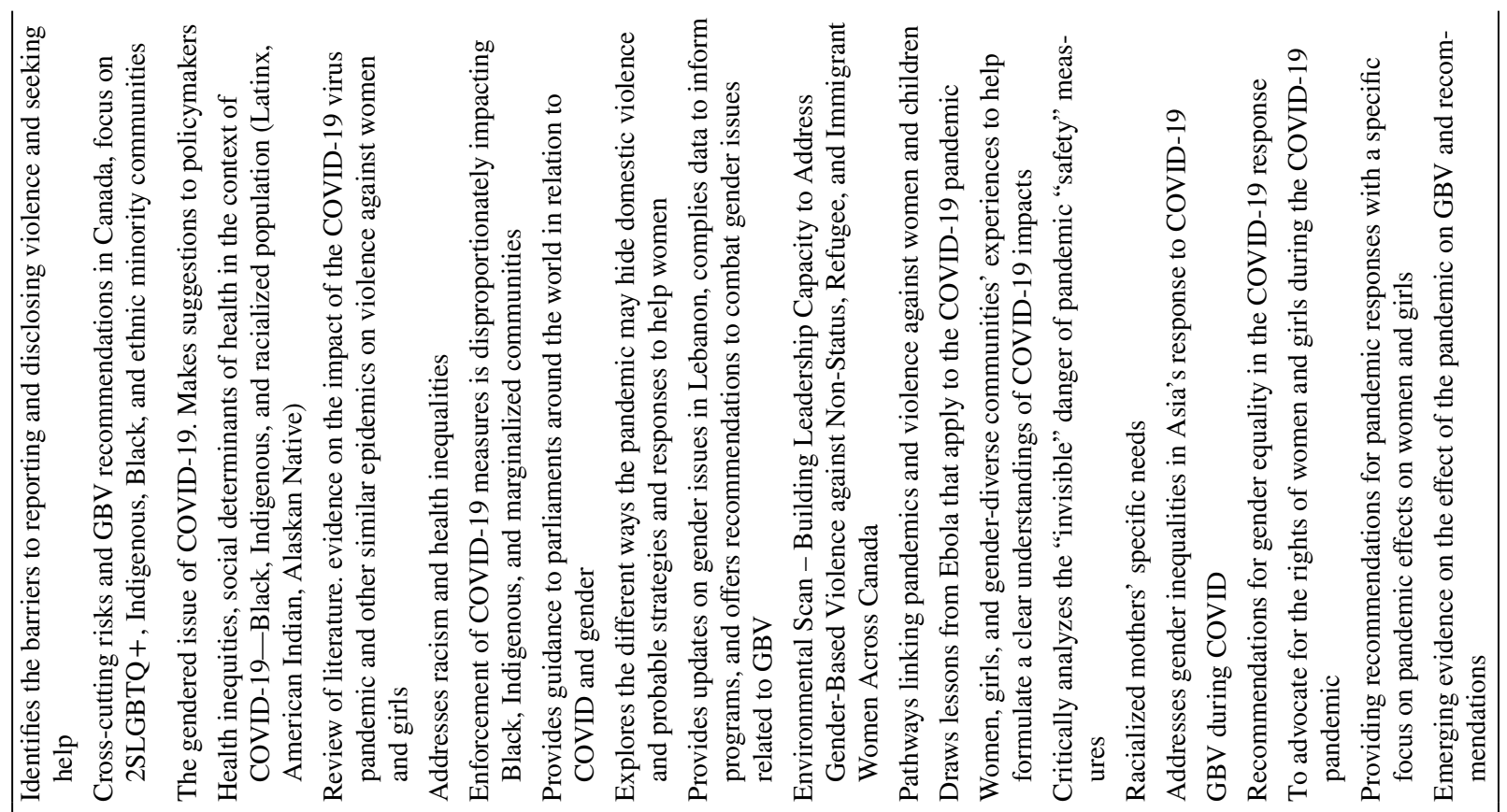

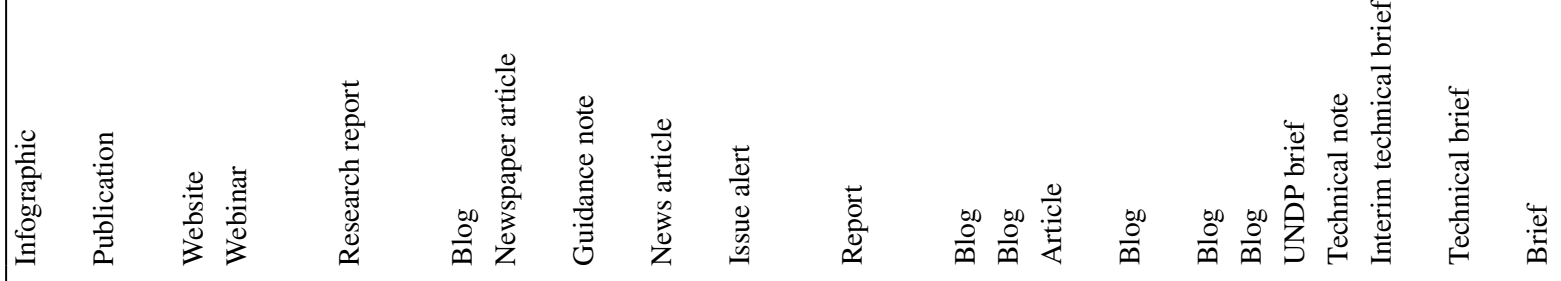

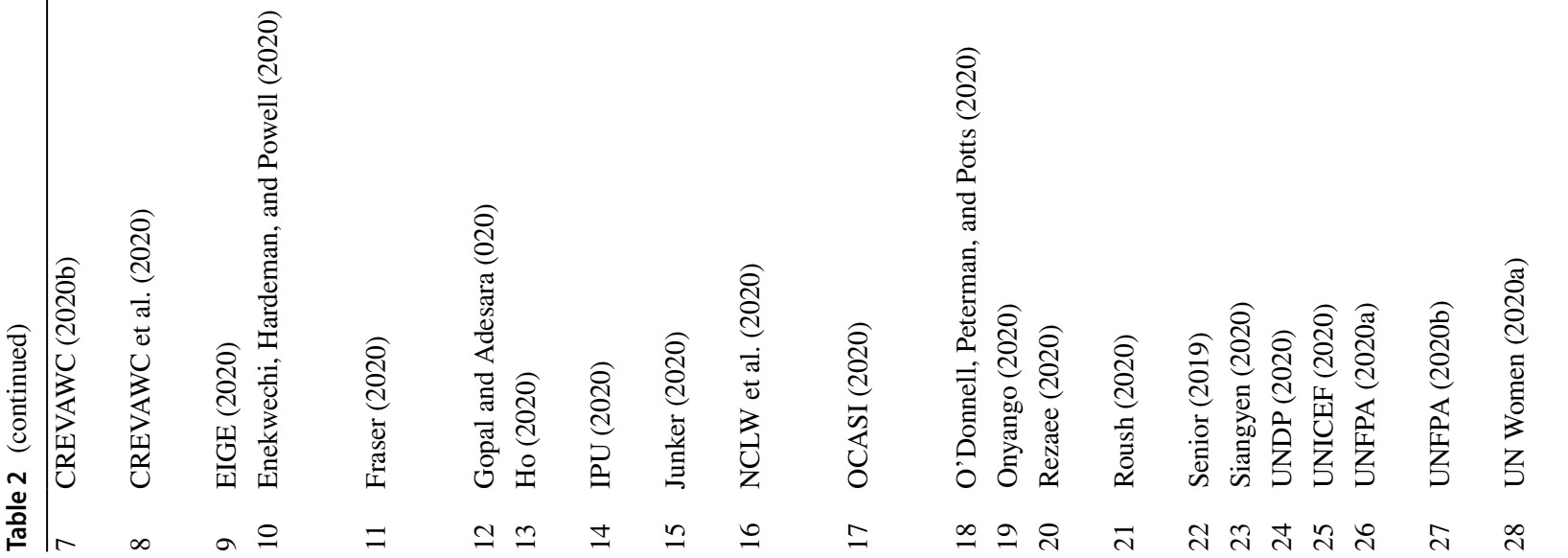


to protect girls at risk of sexual violence in the context of schools closures [52].

Mendenhall [53] argues that framing the current health emergency as a global syndemic is misleading because it overlooks the primary factors that mobilize clustering and disease interaction. Applying a syndemic perspective, Mendenhall [53] observes, allows the integration of the historical legacy of systemic racism, which explains the factors accounting for why and how the coronavirus is moving through the population in the USA, and the interaction with social and biological factors. Critical health researchers recommend application of critical race and intersectional analysis to the study and evaluation of public health response [54]. Health authorities should ensure non-discriminatory access to health care services [47]. Furthermore, to decolonize Indigenous health implies the design of policies that apply Indigenous social determinants of health model [55]. A decolonizing approach to health promotion will address immediate needs as well as structural causes of Aboriginal health inequities [56]. There is also a need to address systemic and micro-racist, microaggression practices in health care provision [57]. There is a need to decolonize care, in other words, to provide racism-free care in the health care system [57].

Gravlee [12] argues that the framework of the syndemics is useful to apply to prevent the danger of reframing the phenomena of Black people being disproportionately impacted by COVID-19, as part of a "intrinsic Black vulnerability." These interpretations, Gravlee explains [12], have emerged and respond to the legacy of racial-genetic discourses in American medicine. Fraser's [27] literature review considered how the current coronavirus pandemic may impact on violence against women and girls. She found that there is limited data on how levels of violence change and are transformed during emergencies, and about the pathways of violence during crises. Data collection is a strategic tool for understanding how and why emergencies such as the COVID-19 pandemic increase violence against women and girls around the world [58]. To address the specific needs of racialized and marginalized communities, institutions should gather disaggregated data including gender, age, sex, race, ethnicity, disability, occupation, socioeconomic status, migratory status, and geographic location [25, 41, 42]. The collection of disaggregated data is also key in planning equitable responses to the pandemic, and in addressing the needs of diverse communities during its different waves and recovery phases. As highlighted by Indigenous scholars, "failure to recognize the differences in morbidity and mortality among Indigenous Peoples contributes to inequities" [32]. page 2739 .

Mental health access points should be promoted to address mental health gaps in communities at greater risks 
Table 3 Selected recommendations with public health and mental health implications

\begin{tabular}{ll}
\hline Recommendations & Implications \\
\hline Gender-responsive COVID-19 programming & $\checkmark$ Consider GBV a public health issue \\
& $\checkmark$ Increased dedicated funding for survivor services and supports \\
& $\checkmark$ Ensure women and girls have access to protections during crises \\
& $\checkmark$ Implement codes of conduct in place to address the endemic violence against female health \\
& workers and sexual harassment in the health sector \\
& $\checkmark$ Engage in multisectoral strategic responses-health, housing \\
& $\checkmark$ Include diversity of voices and perspectives from Black and Indigenous communities, and \\
Intersectional and critical race lenses to emer- & other racialized population, to ensure equity and comprehensive pandemic and post-pan- \\
gency health responses & demic responses \\
& $\checkmark$ Recognize the existence of differentiated primary and secondary effects of the health emer- \\
& gency on marginalized people \\
& $\checkmark$ Apply anti-racism, anti-oppression, and equity policy to service provision \\
& $\checkmark$ Collect disaggregated data - race, gender, sex, ethnicity, age, disability, occupation, socio- \\
Disaggregated data collection & economic status, migratory status, geopolitical location \\
Mental health & $\checkmark$ Expand access points to mental health services \\
GBV referral & $\checkmark$ Conduct mental health audits and inequality impact assessments \\
& $\checkmark$ Update referral pathways and promote institutional multisectoral collaborations
\end{tabular}

Abbreviations: $G B V$, gender-based violence

and with higher disparities [1]. It is recommended to conduct mental health audits and inequality impact assessments of COVID-19 pandemic and post-pandemic policies across all sectors [47]. Furthermore, early in the pandemic we made calls for a public mental health system, to transform our approach to mental health and wellbeing across sectors [59].

GBV referral pathways should be updated to reflect care facilities' availability, and mechanisms to inform communities and service providers [25]. Updates in service directories are needed, and dissemination of this information regularly among strategic networks should be conducted. Collaborations between the health sector and organizations involved in anti-GBV initiatives are needed during emergencies, to provide services effectively and to strengthen referral pathways in accordance with COVID-19 mitigation measures. Updates to referral pathways are important to prevent overwhelming tertiary hospitals [27].

\section{Limitations}

Our review has several of limitations which we acknowledge. First, the peer-reviewed and grey literature on COVID-19 is rapidly growing. Through our search we may have missed more recent peer-reviewed publications, or pertinent grey

Fig. 22020 Syndemic: convergence of COVID-19 pandemic, gender-based violence, and racism

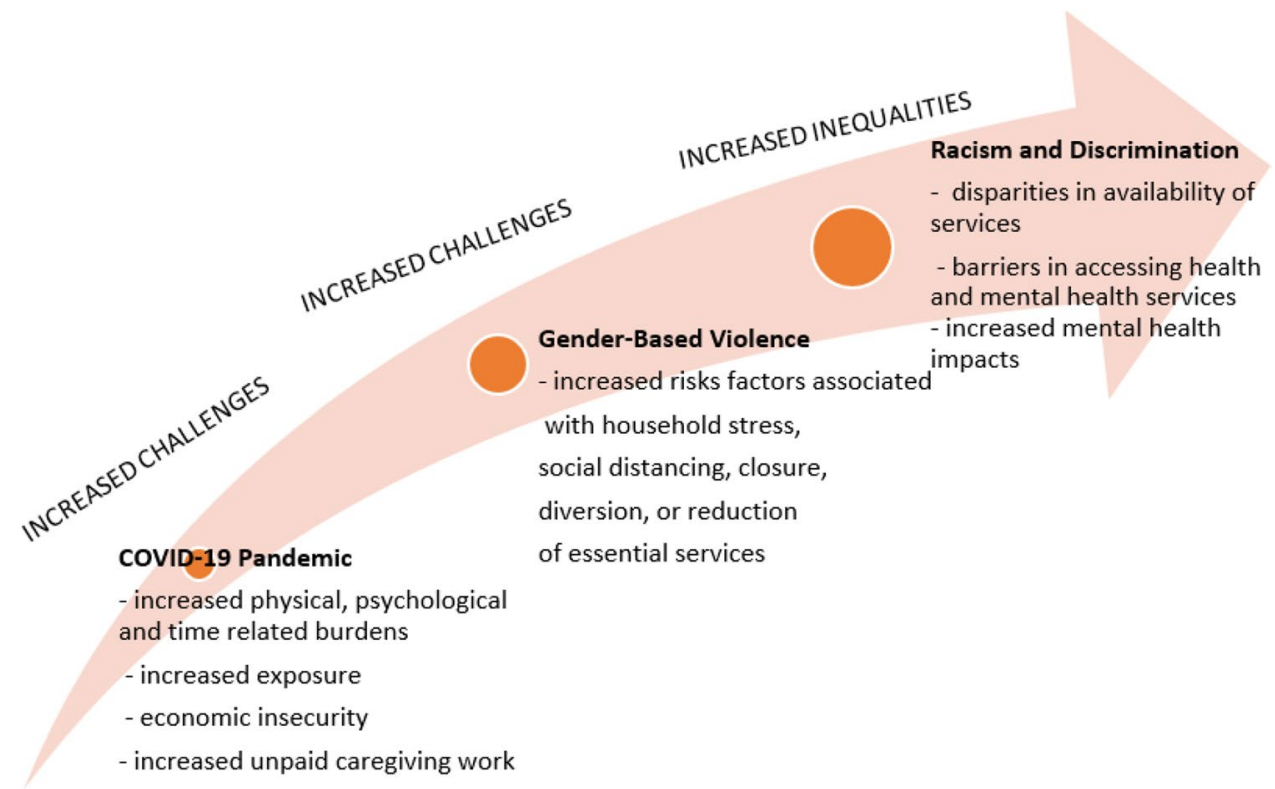


literature that are not posted on publicly available websites or other media. Second, we applied a particular analytical lens to interpreting the findings. While we believe that an intersectionality lens is the most pertinent in addressing the synergistic impact of GBV and racism on women during the COVID-19 pandemic, other researchers may arrive at other interpretations, depending on their theoretical and analytical lens. Third, due to word limitation in journal submission, we did not elaborate on all the literature that we located as part of our synthesis review. We invite interested readers to access our publicly available rapid synthesis findings at https://cihr-irsc.gc.ca/e/52062.html. Finally, our review methodology followed a particular rapid synthesis approach. We did not engage in a full scoping review or a systematic review. However, we believe the Cochrane Rapid Reviews method is well recognized, with detailed steps that allow for repeat of a review for verification purposes by other researchers.

\section{Conclusion}

The experiences of racialized women highlight the differentiated risks, marginalization, social injustices, and inequalities they face, which have been always present, but have compounded in the context of the current COVID-19 pandemic. Drawing from a rapid synthesis of literature, we argue that racialized women are experiencing a 2020 Syndemic: a convergence of COVID-19, gender-based violence, and racism pandemics, placing their wellbeing at a disproportionate risk. We underscore the need to collect disaggregated data and provide recommendations taking into consideration the particular social determinants of mental health of racialized women and girls who have experienced violence during the pandemic.

Acknowledgements We are grateful for the research assistant support of Attia Khan, Negar Alamdar, Amirtha Karunakaran, and Sheena Madzima.

Author Contribution Nazilla Khanlou conceptualized the project and design of the study and supervised all aspects of this work. Luz Maria Vazquez implemented the research and contributed to the analysis of the results and the writing of the manuscript. All other co-authors discussed the results and contributed to the final manuscript by providing feedback.

Funding This review was funded by a Canadian Institutes of Health Research (CIHR) Operating Grant: Knowledge Synthesis: COVID-19 in Mental Health \& Substance Use (2020) to the first author as Principal Investigator and the last author as Principal Knowledge User.

Data availability Not applicable.

Code Availability Not applicable.

\section{Declarations}

Conflict of Interest The authors declare no competing interests.

Open Access This article is licensed under a Creative Commons Attribution 4.0 International License, which permits use, sharing, adaptation, distribution and reproduction in any medium or format, as long as you give appropriate credit to the original author(s) and the source, provide a link to the Creative Commons licence, and indicate if changes were made. The images or other third party material in this article are included in the article's Creative Commons licence, unless indicated otherwise in a credit line to the material. If material is not included in the article's Creative Commons licence and your intended use is not permitted by statutory regulation or exceeds the permitted use, you will need to obtain permission directly from the copyright holder. To view a copy of this licence, visit http://creativecommons.org/licenses/by/4.0/.

\section{References}

1. A. Enekwechi, R. Hardeman and W. Powell, "COVID-19 webinar series session 18 - health inequities: addressing the disease burden in Black, Indigenous, and People of Color Communities [Webinar].," in Alliance for Health Policy, Webinar, 2020 Jun 16.

2. Hooper MW, Nápoles AM, Pérez-Stable E. COVID-19 and racial/ ethnic disparities. JAMA. 2020;323(24):2466-7.

3. UN Women, "Violence against women and girls: the shadow pandemic," 6 April 2020. [Online]. Available: https://www.unwomen. org/en/news/stories/2020/4/statement-ed-phumzile-violence-again st-women-during-pandemic. [Accessed 20 October 2020].

4. E. Roesch, A. Amin, G. Jhumka and C. García-Moreno, "Violence against women during covid-19 pandemic restrictions," BMJ, Vols. 369, 1712, no. m1712, 2020.

5. International Agency Standing Committee (IASC), "Interim Briefing Note. Addressing mental health and psychosocial aspects of COVID-10 outbreak," February 2020. [Online]. Available: https:// interagencystandingcommittee.org/system/files/2020-03/IASC\% 20Interim $\% 20$ Briefing $\% 20$ Note $\% 20$ on $\% 20$ COVID-19\%20Out break\%20Readiness $\% 20$ and $\% 20$ Response $\% 20$ Operations $\% 20-\%$ 20MHPSS_0.pdf. [Accessed 20 June 2020].

6. Dunkle KL, Decker MR. Gender-based violence and HIV: reviewing the evidence for links and causal pathways in the general population and high-risk groups. Am J Reprod Immunol. 2013;69:20-6.

7. Rees S, Silove D, Chey T, Ivancic L, Steel Z, Creamer M, Teesson M, Bryant R, McFarlane AC, Mills KL, Slade T. Lifetime prevalence of gender-based violence in women and the relationship with mental disorders and psychosocial function. JAMA. 2011;306(5):513-21.

8. Tol WA, Stavrou V, Greene MC, Mergenthaler C, Garcia-Moreno C, Van Ommeren M. Mental health and psychosocial support interventions for survivors of sexual and gender-based violence during armed conflict: a systematic review. World Psychiatry. 2013;12(2):179-80

9. J. R. Rezaee, "An intersectional approach to COVID 19 she covery. YWCA Toronto, A Turning Point for Women, United Way," 27 May 2020. [Online]. Available: https://www.ywcatoronto.org/ takeaction/additional/intersectional. [Accessed 20 June 2020].

10. Mendenhall E. Syndemics: a new path for global health research. Lancet. 2017;389:889-91.

11. Willen S, Knipper M, Abadía-Barrero CE, Davidovitch N. Syndemic vulnerability and the right to health. Lancet. 2017;389:964-77. 
12. C. G. Gravlee, "Systemic racism, chronic health inequities, and COVID-19: a syndemic in the making?," American Journal of Human Biology, 2020.

13. Editorial, "Syndemics: health in context," Lancet, vol. 389, no. 10072, p. 881, 2017.

14. Singer M, Rylko-Bauer B. The syndemics and structural violence of the COVID pandemic: anthropological insights on a crisis. Open Anthropological Research. 2020;1(1):7-32.

15. Horton R. Offline: COVID-19 is not a pandemic. Lancet (London, England). 2020;396(10255):874.

16. Singer M, Bulled N, Ostrach B, Mendenhall E. Syndemics and the biosocial conception of health. The Lancet. 2017;389(10072):941-50.

17. Hall CX, Evans DP. Social comorbidities? A qualitative study mapping syndemic theory onto gender-based violence and cooccurring social phenomena among Brazilian women. BMC Public Health. 2020;20(1):1-12.

18. N. Kline, "Syndemic statuses: Intersectionality and mobilizing for LGBTQ+ Latinx health equity after the Pulse shooting," Social Science \& Medicine 2020113260

19. Crenshaw K. Mapping the margins: intersectionality, identity politics, and violence against women of color. The public nature of violence: the discovery of domestic abused. Stanford Law Review. 1989;436:93-117.

20. Khanlou N, Ssawe A, Vazquez LM, Pashang S, Connolly JA, Bohr Y, Epstein I, Zahraei S, Ahmad F, Mgwigwi T, Alamdar N. COVID-19 pandemic guidelines for mental health support of racialized women at risk of genderbased violence: Knowledge synthesis report. Funded by Canadian Institutes of Health Research (CIHR) Operating Grant: Knowledge Synthesis: COVID-19 in Mental Health \& Substance Use. York University; 2020. https://cihr-irsc.gc.ca/e/52062.html

21. Cochrane COVID Rapid Reviews., "Resources for author teams. Rapid Review Full review template," 2020. [Online]. Available: https://covidrapidreviews.cochrane.org/resources. [Accessed 20 October 2020].

22. Centers for Disease Control and Prevention (CDCP), "Health equity considerations and racial and ethnic minority groups. US Department of Health and Human Services" 2020.

23. International Labour Organization, "The gender gap in employment: what's holding women back?," International Labour Organization 2018.

24. UNICEF, "Five actions for gender equality in the COVIDresponse. UNICEF Technical Note," UNICEF, New York, 2020.

25. UNFPA, "Coronavirus disease (COVID-19) preparedness and response. UNFPA Interim Technical Briefs. Gender equality and addressing gender-based violence (GBV) and coronavirus disease (COVID-19) prevention, protection and response," 2020.

26. John N, Casey SE, Carino G, McGovern T. Lessons never learned: crisis and gender-based violence. Dev World Bioeth. 2020;20(2):65-8.

27. E. Fraser, "Impact of COVID-19 pandemic on violence against women and girls, VAWG. Helpdesk Research Report No. 284," VAWG Helpdesk, London, UK 2020.

28. F. Gabriele, K. Sapoznik, A. Serojitdinov and E. Williams, "The incidence of human trafficking in Ontario: Ontario Coalition Research Initiative," Alliance against Modern Slavery, 2014.

29. D. A. Gibbs, J. H. Walters, A. Lutnick, S. Miller and M. Kluckman, "Services to domestic minor victims of sex trafficking: opportunities for engagement and support" Children and Youth Services Review 54 1-7.

30. M. O'Donnell, A. Peterman and A. Potts, "A gender lens on covid-19: Pandemics and violence against women and children. Center for Global Development," 2020

31. Center for Research \& Education on Violence Against Women \& Children (CREVAWC), "Factors that contribute to risks and vulnerabilities associated with IPV in immigrant and refugee communities," 2020a. [Online]. Available: http://www.vawle arningnetwork.ca/our-work/infographics/ipv-imm-ref/Factorsthat-Contribute-to-Risks-and-Vulnerabilities-associated-withIPV-in-Immigrant-and-Refugee-Communities.jpg. [Accessed 21 October 2020].

32. Power T, Wilson D, Best O, Brockie T, Bourque Bearskin L, Millender E, Lowe J. "COVID-19 and Indigenous Peoples an imperative for action." J Clin Nurs. 2020;29(15-16):2737-41.

33. Hall KS, Samari G, Garbers S, Casey SE, Diallo DD, Orcutt M, McGovern T. Centring sexual and reproductive health and justice in the global COVID-19 response. Lancet. 2020;395:1175-7.

34. Burzinkska K, Contreras G. Gendered effects of school closures during the COVID-19 pandemic. The Lancet. 2020;95(10242):1968.

35. Center for Research \& Education on Violence Against Women \& Children- Learning Network (CREVAWC), "COVID-19 \& gender-based violence in Canada: key issues and recommendations," vawlearningnetwork.ca, London, ON, 2020b.

36. R. R. Sinclair, T. Allen, L. Barber, M. Bergman, T. Britt, A. Butler and M. Ford, "Occupational health science in the time of COVID19: now more than ever." (2020): 1-22.," vol. 4, pp. 1-22, 2020.

37. A. Craft, D. McGregor and J. Hewitt, "COVID-19 and First Nations' responses," in Vulnerable. The law, policy and ethics of COVID-19, J. Philpott, S. Theriault and S. Venkatapura, Eds., Ottawa, ON, University of Ottawa Press, 2020, pp. 49-67.

38. A. Levesque and S. Thériault, "Systemic discrimination in government services and programs and its impact on First Nations peoples during the COVID-19. In Pandemic," in Vulnerable. The law, policy and ethics of COVID, J. Philpott, S. Theriault and S. Venkatapura, Eds., Ottawa, ON, University of Ottawa Press, 2020, pp. 381-392.

39. The COVID Tracking Project, "The COVID racial data tracker. COVID-19 is affecting Black, Indigenous, Latinx, and other people of color the most," 2020.

40. City of Toronto, "COVID-19: status of cases in Toronto," 2020. [Online]. Available: https://www.toronto.ca/home/covid-19/covid19-latest-city-of-toronto-news/covid-19-status-of-cases-in-toron to/. [Accessed 1 August 2020].

41. Center for Research \& Education on Violence Against Women \& Children- Learning Network, Wester University (CREVAWC) Women's Shelter Canada et al. , "COVID-19 \& gender based violence in Canada: key issues and recommendations," Center for Research \& Education on Violence Against Women \& ChildrenLearning Network, 2020.

42. Siangyen C. Stop widening gender inequalities: Asia's COVID19 responses must leave no one behind. The Development Policy Centre Blog. Development Policy Centre: Australian National University, Canberra; 2020.

43. M. B. Kumar and M. Tjepkema, "National household survey: aboriginal peoples suicide among First Nations people, Métis and Inuit (2011-2016): findings from the 2011 Canadian Census Health and Environment Cohort (CanCHEC)," 28 June 2019. [Online]. Available: https://www150.statcan.gc.ca/n1/pub/99011-x/99-011-x2019001-eng.htm. [Accessed 30 Ocober 2020].

44. Statistics Canada, "Impacts of COVID-19 on Canadians - perceptions of safety," Minister of Industry, Ottawa, ON, 2020

45. Le TK, Cha L, Han HR, Tseng W. Anti-Asian xenophobia and Asian American COVID-19 disparities. Am J Public Health. 2020;110(9):1371-3.

46. E. Jenkins, A. Gadermann and C. McAuliffe, "Mental health impact of coronavirus pandemic hits marginalized groups hardest," The Conversation, Available url: https://theconversation. $\mathrm{com} / \mathrm{mental}$-health-impact-of-coronavirus-pandemic-hits-margi nalized-groups-hardest-142127, 26 July 2020. 
47. N. Rose, N. Manning, R. Bentall, K. Bhui , R. Burgess, S. Carr, F. Cornish, D. Devakumar, J. B. Dowd, S. Ecks, E. Faulkner, A. R. Keene, J. Kirkbride, M. Knapp, A. M. Lovell, P. Martin, J. Moncrieff, H. Parr, M. Pickersgill, G. Richardson and S. Sheard, "The social underpinnings of mental distress in the time of COVID19 -time for urgent action [version 1; peer review: 4 approved]," Wellcome Open Res 20205166.

48. Native Women's Association of Canada, "The impact of COVID19 on Indigenous Peoples. Submission to the UN Special Rapporteur on the Rights of Indigenous Peoples. Submission to the UN Special Rapporteur on the Rights of Indigenous Peoples. Ottawa, ON: The Native Women's Association of Canada," Native Women's Association of Canada (NWAC), Ottawa, ON, 2020

49. Canadian Mental Health Association, "COVID-19 effects on the mental health of vulnerable populations," 24 June 2020. [Online]. Available: https://cmha.ca/documents/covid-mental-health-effec ts-on-vulnerable-populations. [Accessed 23 October 2020].

50. UN Women, "Violence against women and girls data collection during COVID-19," UN Women Headquarters, 2020 April 17.

51. Ostrach B, Singer M. At special risk: biopolitical vulnerability and HIV/STI syndemics among women. Health Sociol Rev. 2012;21(3):258-71.

52. Inter-Parliamentary Union (IPU), "Gender and COVID-19: a guidance note for parliaments," 2020. [Online]. Available: https:// www.ipu.org/gender-and-covid-19-guidance-note-parliaments. [Accessed 30 October 2020].

53. Mendenhall $\mathrm{E}$. The COVID-19 syndemic is not global: context matters. The Lancet. 2020;10264(1731):396.
54. J. Chai, "Spread of anti-Asian racism: prevention and critical race analysis. In Pandemic," in Vulnerable. The law, policy and ethics of COVID-19, J. Philpott, S. Theriault and S. Venkatapura, Eds., Ottawa, ON, University of Ottawa Press, 2020, pp. 393-405.

55. K. Jacklin and W. Warry, "Decolonizing first nations health. Health in rural Canada," in Health in Rural Canada, A. Williams and J. C. Kulig, Eds., Vancouver, British Columbia, UBC Press, 2011, pp. 373-389.

56. Mundel E, Chapman GE. A decolonizing approach to health promotion in Canada: the case of the Urban Aboriginal Community Kitchen Garden Project. Health Promot Int. 2010;25(2):166-73.

57. Moorley C, Ferrante J, Jennings K, Dangerfield A. Decolonizing care of Black, Asian and Minority Ethnic patients in the critical care environment: a practical guide. Nurs Crit Care. 2020;25(5):324-6.

58. UN Women, "COVID-19 and ending violence against women and girls. United Nations Entity for Gender Equality and the Empowerment of Women," 2020.

59. Khanlou, N. Editorial: Call for a Canadian public mental health system: Transformative change amid a global pandemic. J Concurrent Dis. 2020;2(1), 1-2. https://concurrentdisorders.ca/2020/03/ 31/call-for-a-canadian-public-mentalhealth-system.

Publisher's Note Springer Nature remains neutral with regard to jurisdictional claims in published maps and institutional affiliations. 